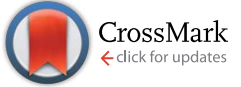

Cite this: Chem. Sci., 2017, 8, 1195

Received 23rd June 2016

Accepted 30th September 2016

DOI: $10.1039 / c 6 s c 02790 c$

www.rsc.org/chemicalscience

\title{
The dual role of thiourea in the thiotrifluoromethylation of alkenes $\uparrow$
}

\author{
Paolo Ricci,,$^{a}$ Tanatorn Khotavivattana, $\hbar^{a}$ Lukas Pfeifer, ${ }^{a}$ Maurice Médebielle, ${ }^{b}$ \\ John Richard Morphy ${ }^{c}$ and Véronique Gouverneur*a
}

\begin{abstract}
Alkenes substituted with a thiourea undergo $\mathrm{C}-\mathrm{CF}_{3}$ followed by intramolecular $\mathrm{C}-\mathrm{S}$ bond formation with the Togni reagent and trifluoroacetic acid (TFA) at room temperature; thiols and thioamides are not suitable $\mathrm{S}$-sources for this reaction. This anti-addition process involves a $\mathrm{CF}_{3}$ radical, and affords $\mathrm{CF}_{3}-$ substituted thiazolines and thiazines for medicinal applications. A metal or photoredox catalyst is not required as the thiourea acts as a reductant, as well as serving as an S-source capable of adding to a Ccentered radical. Mechanistic work comparing the reactivity of thiourea, urea, thioamide and thiol in the context of alkene trifluoromethylation demonstrates that in this series, the thiourea is unique for its ability to release $\mathrm{CF}_{3}$ radical from the Togni reagent, and to orchestrate trifluoromethylation followed by $S$-cyclization with both activated and unactivated alkenes.
\end{abstract}

\section{Introduction}

A large number of pharmaceuticals contain a trifluoromethyl group because this structural motif affects the properties of organic molecules. ${ }^{1}$ The installation of trifluoromethyl groups onto $\mathrm{sp}^{3}$ hybridized carbon has progressed significantly with numerous addition reactions of $\mathrm{CF}_{3}$ across alkenes. Alkene vicinal functionalizations featuring $\mathrm{C}-\mathrm{CF}_{3}$ combined with $\mathrm{C}-\mathrm{H}$, $\mathrm{C}-\mathrm{C}$ or C-heteroatom bond formation have been disclosed, most requiring a transition metal or photoredox catalyst to activate the $\mathrm{CF}_{3}$ reagent (Scheme 1a). ${ }^{2}$ Vicinal difunctionalizations involving sulfur heteroatom are notoriously rare; this process is much more challenging as, in contrast to amines and alcohols, thiols undergo facile $S$-trifluoromethylation with the Togni or Umemoto reagents in the absence of catalyst. ${ }^{3}$ A case of alkene thiotrifluoromethylation was reported by Langlois in $2000 .{ }^{4}$ In this process, photolysis of $\mathrm{CF}_{3} \mathrm{SO}_{2} \mathrm{SPh}$ generates a $\mathrm{CF}_{3}$ radical $\left(\mathrm{CF}_{3}{ }^{\circ}\right)$ that adds to the alkene; this step affords a weakly nucleophilic radical that reacts with $\mathrm{CF}_{3} \mathrm{SO}_{2} \mathrm{SPh}$ to provide the thioether product and the chain propagating trifluoromethylsulfonyl radical. The reagent in this reaction serves

${ }^{a}$ Chemistry Research Laboratory, Department of Chemistry, Oxford University, OX1 3TA, UK. E-mail: veronique.gouverneur@chem.ox.ac.uk; Fax: +44 (0)1865 285002

${ }^{b}$ Université de Lyon, Université Claude Bernard Lyon I, ICBMS UMR CNRS - UCBL CPE - INSA 5246, Equipe Synthèse de Molécules d'Intérêt Thérapeutique (SMITh), 43 bd du 11 Novembre 1918, Villeurbanne 69622, France

${ }^{c}$ Medicinal Chemistry, Eli Lilly and Company Limited, Erl Wood Manor, Sunninghill Road, Windlesham, Surrey, GU20 6PH, UK

$\dagger$ Electronic supplementary information (ESI) available. CCDC 1474239-1474241. For ESI and crystallographic data in CIF or other electronic format see DOI: $10.1039 / \mathrm{c} 6 \mathrm{sc} 02790 \mathrm{c}$

$\ddagger$ These authors contributed equally to this work. both as $\mathrm{CF}_{3}$ and S-source, thereby minimizing $\mathrm{S}_{-} \mathrm{CF}_{3}$ bond formation. In a related approach, Zard reported the net addition of $S$-trifluoromethyl xanthates reagents onto alkenes, a process initiated with lauroyl peroxide. ${ }^{5}$ The abundance of sulfur containing heterocycles in medicinal chemistry ${ }^{6}$ prompted us to study alkene difunctionalization via $\mathrm{C}_{-} \mathrm{CF}_{3}$ and $\mathrm{C}-\mathrm{S}$ bond formation where the $\mathrm{CF}_{3}$ and SR groups would not stem from a single reagent. In 2015, Liu and co-workers reported a case of intermolecular difunctionalization with the copper-catalyzed

a) trifluoromethylation/heterocyclization of alkenes

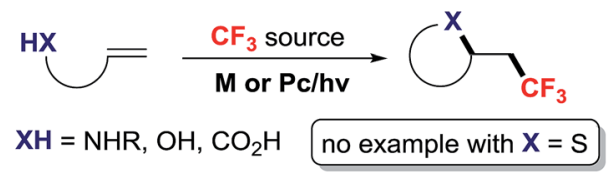

b) bioactive 2-amino-thiazines and -thiazolines

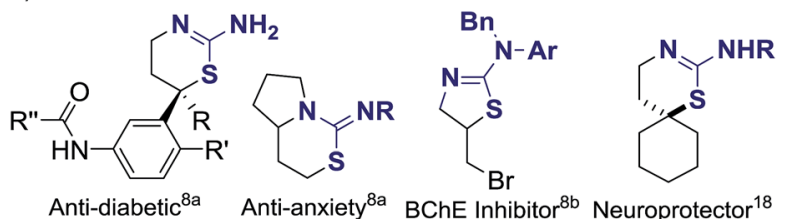

c) trifluoromethylation/thiocyclization of alkenes (this work)

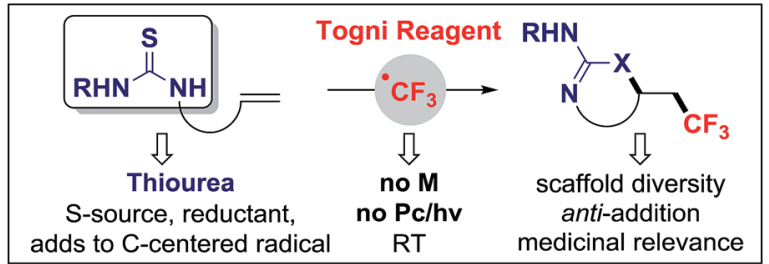

Scheme 1 Trifluoromethylation/thiocyclization of alkenes $(M=$ metal, $\mathrm{Pc}=$ photoredox catalyst). 
trifluoromethylthiocyanation of alkenes; this process requires trimethylsilylisocyanate, a silicon-based S-source that acts as Lewis acid to activate the Togni reagent. ${ }^{7}$

In our design plan, we opted to examine the reactivity of olefins with pending thioureas, a decision driven by synthetic and mechanistic considerations. Trifluoromethylation followed by $\mathrm{C}-\mathrm{S}$ bond formation would afford novel trifluoromethylated 2-amino-thiazolines and 2-amino-thiazines for applications in medicinal chemistry. ${ }^{8}$ Selected 2-amino-thiazines and -thiazolines are important scaffolds in the development of aspartate beta-secretase enzyme (BACE-1) inhibitors, a therapeutic target for Alzheimer's disease, ${ }^{9}$ and are common motifs in several bioactive compounds (Scheme 1b). Mechanistically, the ability of thioureas to act as reducing agent ${ }^{10}$ and radical scavenger ${ }^{11}$ suggests that this group may induce the release of $\mathrm{CF}_{3} \cdot$ from the Togni reagent, ${ }^{12}$ and serve as an S-source capable of adding on a C-centered radical. Here we report that thiourea-substituted alkenes undergo $\mathrm{C}-\mathrm{CF}_{3}$ followed by $\mathrm{C}-\mathrm{S}$ bond formation with the Togni reagent and TFA. This operationally simple reaction does not require a metal catalyst, and affords diverse $\mathbf{C F}_{3^{-}}$ substituted 2-amino-thiazolines and thiazines resulting from overall anti-addition across the $\mathrm{C}=\mathrm{C} \pi$ bond (Scheme 1c).

\section{Results and discussion}

To identify suitable reaction conditions, we selected the unactivated alkene 1aa, and the Togni $\mathbf{I}, \mathbf{I I}^{\mathbf{1 3}}$ and Umemoto $\mathbf{I I I}^{\mathbf{1 4}}$ reagents as $\mathrm{CF}_{3}$ source (Table 1$) .{ }^{15}$ The desired 2-amino-thiazoline 2 aa resulting from trifluoromethylation followed by $S$ -

Table 1 Optimization of reaction parameters

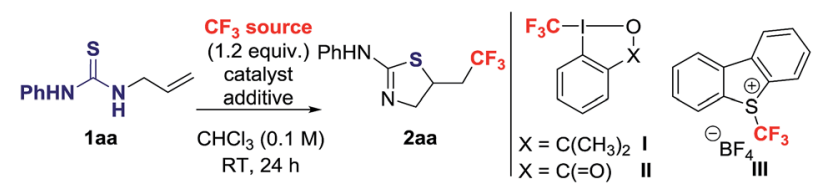

\begin{tabular}{|c|c|c|c|c|}
\hline Entry & $\mathrm{CF}_{3}$ source & Catalyst & Additive & Yield $^{a}(\%$ \\
\hline 1 & I & - & - & 7 \\
\hline 2 & II & - & - & $33,21^{b}$ \\
\hline 3 & III & - & - & $12,7^{b}$ \\
\hline 4 & II & - & TFA ( 2 equiv.) & $76,62^{c}$ \\
\hline 5 & II & - & TFA (1 equiv.) & 69 \\
\hline 6 & III & - & TFA ( 2 equiv.) & 13 \\
\hline $7^{d}$ & II & - & TFA ( 2 equiv.) & 59 \\
\hline 8 & II & $\mathbf{A}(5 \mathrm{~mol} \%)$ & - & 21 \\
\hline 9 & II & A $(100 \mathrm{~mol} \%)$ & B (1 equiv.) & 33 \\
\hline $10^{e}$ & II & C (5 mol\%) & - & 20 \\
\hline $11^{e}$ & II & D $(2 \mathrm{~mol} \%)$ & - & 31 \\
\hline $12^{e}$ & III & C $(5 \mathrm{~mol} \%)$ & - & 40 \\
\hline $13^{e}$ & III & D $(2 \mathrm{~mol} \%)$ & - & 38 \\
\hline
\end{tabular}

${ }^{a}$ Determined by ${ }^{19} \mathrm{~F}$ NMR integration relative to an internal standard $\left(\mathrm{C}_{6} \mathrm{H}_{5} \mathrm{CF}_{3}\right) .{ }^{b}$ Reaction at $60{ }^{\circ} \mathrm{C} .{ }^{c}$ Reaction time is $1 \mathrm{~h} .{ }^{d}$ Reaction in $\mathrm{CH}_{3} \mathrm{CN} .{ }^{e} 14 \mathrm{~W}$ bulb as light source $\left(\lambda_{\max }=452 \mathrm{~nm}\right) \cdot \mathrm{A}=$ $\mathrm{Cu}\left(\mathrm{CH}_{3} \mathrm{CN}\right)_{4} \mathrm{PF}_{6} . \mathrm{B}=1,10$-phenantroline. $\mathrm{C}=\mathrm{Ru}(\mathrm{bpy})_{3}\left(\mathrm{PF}_{6}\right)_{2} . \mathrm{D}=$ methylene blue. TFA $=$ trifluoroacetic acid. cyclization was formed in low yield when the reaction was carried out at room temperature in $\mathrm{CHCl}_{3}$ with I, II or III in the absence of catalyst or additive (Table 1, entries 1-3). No sideproducts resulting from oxidative dimerization or $\mathrm{S}-\mathrm{CF}_{3}$ bond formation were detected. The conversion of 1aa into 2aa decreased at $60{ }^{\circ} \mathrm{C}$ (Table 1 , entries 2 and 3).

Activation of the Togni reagents by protonation with BrØnsted acid is well documented, ${ }^{\mathbf{1 6}}$ but not typically considered for $\mathrm{CF}_{3}$ addition onto alkenes. We envisioned that upon protonation of II with trifluoroacetic acid (TFA), the resulting highly electrophilic iodine centre could undergo S-I(III) coordination with the thiourea functionality followed by single electron transfer (SET) with more effective release of $\mathrm{CF}_{3}$ radical. Gratifyingly, $62 \%$ of $2 \mathrm{aa}$ was observed after $1 \mathrm{~h}$ when the reaction was conducted in the presence of 2 equiv. of TFA, and the yield reached $76 \%$ after $24 \mathrm{~h}$ (Table 1 , entry 4 ). The reaction was less effective using 1 equiv. of TFA (Table 1, entry 5). The presence of the acid did not induce protocyclization, and its benefit was not significant with Umemoto III (Table 1, entry 6).

With the conditions described in entry 4 of Table 1 , the scope of the thiotrifluoromethylation was investigated (Scheme 2). Allyl and metallyl thioureas afforded 2-amino-thiazolines 2aa and 2 ba in $80 \%$ and $96 \%$, respectively. A range of parasubstituted styrenes underwent thiotrifluoromethylation with yields up to $92 \%$. The reaction was extended to 1,2-dihydronaphthalenes, $2 \mathrm{H}$-chromene, $2 \mathrm{H}$-thiochromene and indene; in this series, all thiazolines were formed as a single stereoisomer resulting from anti-addition (d.r. > $20: 1) .{ }^{17}$ The 1,2-dihydronaphthalene scaffold was selected to investigate the tolerance of the reaction to variation of the thiourea $N$-substituent. The resulting products anti-2ga-2gl were isolated in yields ranging from $53 \%$ to $83 \%$. No reaction occurred with 1 gm, a substrate possessing the free $\mathrm{NH}_{2}$ sub-motif. The corresponding 2-aminothiazoline $2 \mathbf{g m}$ was obtained by a detour pathway involving in situ deprotection of the $N$ - $t$ Bu group of 2 gi under acidic conditions. The thiotrifluoromethylation of the chiral substrate 1-(1(3,4-dihydronaphthalen-1-yl)propyl)-3-phenylthiourea provided adduct $2 \mathrm{gn}$ in moderate yield as a mixture of diastereomers (ratio $=3.5: 1){ }^{15}$ Thiazines are also within reach applying this methodology. The spirocyclic product 2 ka was obtained in $53 \%$ yield and an eroded d.r. = 6:1 favoring the anti-isomer. Styrenes, with different points of attachment for the thiourea, delivered additional trifluoromethylated scaffolds. The 2,2,2trifluoroethyl-substituted $4 H$-benzo $[d][1,3]$-thiazin-2-amines 2 la and $2 \mathrm{ma}$ were obtained in moderate yields. Products possessing the $\mathrm{CF}_{3}$ group on the thiazine ring itself were accessible from 3substituted 1-cinnamyl-thioureas; for example, 2na was isolated in $40 \%$ yield with a d.r. $>20: 1$. In this series, substituents on the aryl rings are well tolerated. The reaction with the internal alkyl-substituted alkene, (E)-1-(hex-2-en-1-yl)-3-phenylthiourea delivered a mixture of 5-exo- and 6-endo-regioisomers in a $\sim 1: 1$ ratio (isolated yields were $22 \%$ and $20 \%$, respectively). ${ }^{15}$ The spirocyclic thiazine anti-2ra, a $\mathrm{CF}_{3}$-substituted analogue of a neuroprotector, ${ }^{18}$ was prepared in $60 \%$ yield (d.r. $>20: 1$, after purification). A larger scale reaction on $2.3 \mathrm{mmol}$ provided consistent yield of 2 ra (61\%), an indicator of the robustness of the process. Thiazine 2rc is a trifluoromethylated analogue of 


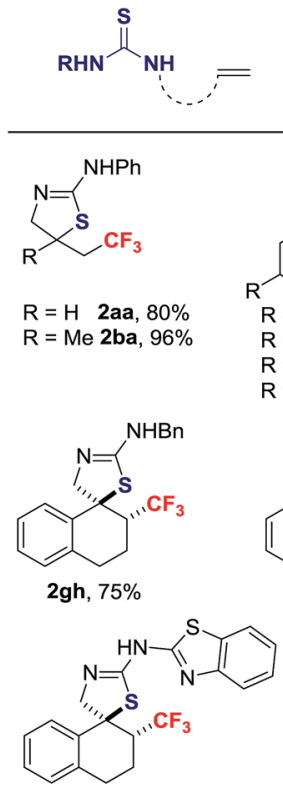

2gj, $58 \%$<smiles>NC1=NCC2(S1)c1ccccc1CC[C@H]2C(F)(F)F</smiles>

2gm, $0 \%(79 \%)^{c}$

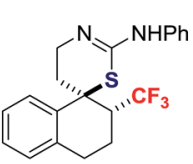

2ka, $53 \%$ b,e<smiles>[R]NC1=NCC[C@@]2(CCCC[C@H]2F)S1</smiles>

$\mathrm{R}=\mathrm{Ph} \quad$ 2ra, $60 \%$ e,f $\mathrm{R}=\mathrm{PMB} \quad 2 \mathrm{rb} 47 \%^{\mathrm{g}}$ $\mathrm{R}=\mathrm{H} \quad 2 \mathrm{rc} 0 \%(34 \%)^{\mathrm{c}, \mathrm{g}}$

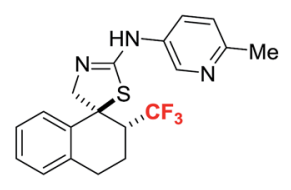

2gl, 53\%

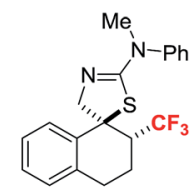

2gk, $75 \%$
RHN

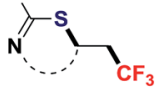

RT 24 r

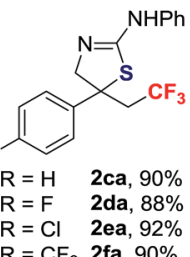

$\mathrm{Ar}=(4-\mathrm{Br}) \mathrm{Ph}$
$\mathrm{Ar}=(4-\mathrm{I}) \mathrm{Ph}$

2gd, 79\%

$\mathrm{Ar}=\left(4-\mathrm{CO}_{2} \mathrm{Me}\right) \mathrm{Ph} 2 \mathrm{2gg}, 64 \%$

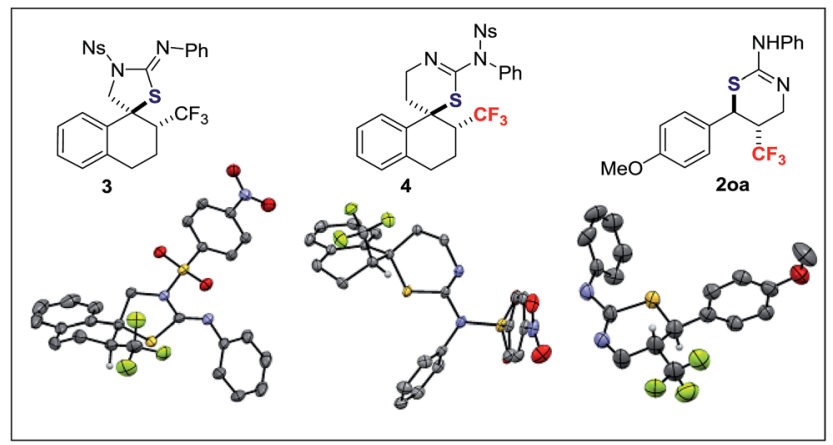

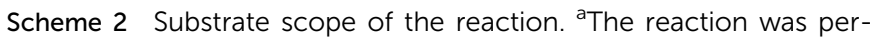
formed on a $0.3 \mathrm{mmol}$ scale; yield of isolated product; d.r. $>20: 1$ by ${ }^{19} \mathrm{~F}$ NMR of crude reaction. ${ }^{b}$ Relative configuration established by single crystal $X$-ray diffraction analysis; for $2 \mathrm{ga}$ and $2 \mathrm{ka}$, analysis was performed on the derivatives 3 and 4, respectively. ${ }^{\mathrm{C}} 2 \mathrm{gm}$ and $2 \mathrm{rc}$ were obtained by in situ deprotection of $2 \mathrm{gi}$ and $2 \mathrm{rb}$, respectively; yields from the alkene. ${ }^{d}$ d.r. $=3.5: 1 .{ }^{e}$ d.r. $=6: 1 .{ }^{f} 61 \%$ yield when the reaction was scaled up to $2.3 \mathrm{mmol}$. ${ }^{9}$ d.r. $=5: 1$. PMB $=$ paramethoxybenzyl. a scaffold found in BACE-1 inhibitors for treating Alzheimer's disease ${ }^{19}$ this thiazine was obtained by deprotection with CAN of the $N$-PMB group of 2 rb. Finally, the method also gave access to the $\mathrm{CF}_{3}$-containing thiazepine $2 \mathbf{s a}$.

\section{Mechanistic experiments}

We probed the mechanism of this reaction with a series of experiments (Scheme 3). The presence of 1 equiv. of TEMPO significantly inhibited the thiotrifluoromethylation of 1aa, yielding $23 \%$ of TEMPO-CF 3 and $6 \%$ of $2 \mathbf{a a}^{15}$ Complete inhibition for the formation of 2aa was observed in the presence of benzoquinone. The cyclopentane 5 was isolated in $20 \%$ yield when diethyl 2,2-diallylmalonate was submitted to the reaction conditions in the presence of 1 equiv. of $N, N$-diphenylthiourea (DPTU); ${ }^{20}$ in the absence of thiourea, no reaction occurred (eqn (1)). Both $E$-1na and $Z$-1na gave anti-2na with d.r. $>20: 1$ (eqn (2)). Collectively, these data indicate that a $\mathrm{CF}_{3}$ radical is involved in the reaction.

Next, we investigated the uniqueness of the thiourea functionality for its ability to induce $\mathrm{CF}_{3}$ formation. We compared the reactivity of the thiourea 1ga with the corresponding urea 6

$$
\begin{aligned}
& \sum_{\mathrm{EtO}_{2} \mathrm{C}}^{\|} \mathrm{PhHN}_{\mathrm{CO}_{2} \mathrm{Et}}^{\mathrm{S}} \|_{\mathrm{NHPh}}^{\frac{\mathrm{TFA}(2 \text { equiv. })}{\mathrm{CHCl}_{3}, \mathrm{RT}, 24 \mathrm{~h}}} \\
& \text { or } \\
& \text { Tha II (1.2 equiv.) } \\
& X=\mathrm{S}, Y=\text { NHPh, 1ga } \\
& \mathrm{X}=\mathrm{O}, \mathrm{Y}=\mathrm{NHPh}, \mathbf{6} \\
& X=\mathrm{O}, \mathrm{Y}=\mathrm{NHPh}, \mathbf{6}+\text { DPTU (1 equiv.) } \\
& X=O, Y=P h, 8 \\
& X=O, Y=P h, 8+D P T U \text { (1 equiv.) }
\end{aligned}
$$

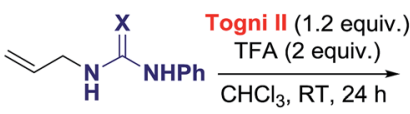

$$
\begin{aligned}
& X=S, 1 \text { aa } \\
& \mathrm{X}=\mathrm{O}, 10 \\
& X=O, 10+\text { DPTU (1 equiv.) }
\end{aligned}
$$

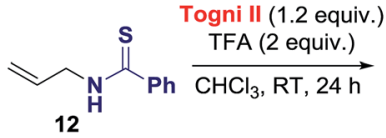

$$
\begin{aligned}
& \text { 2ga, } 87 \% \quad \text { (eq. 3) } \\
& \text { 7, } 0 \% \text { (no reaction) } \\
& \text { 7, } 13 \% \\
& 9,0 \% \text { (no reaction) } \\
& \text { 9, } 22 \%
\end{aligned}
$$
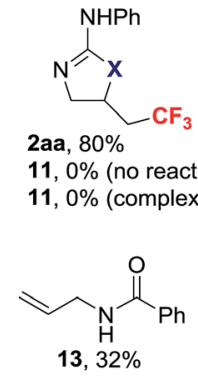

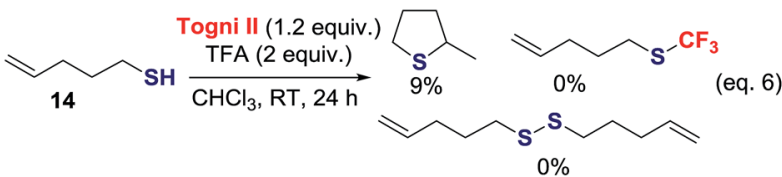

Scheme 3 Mechanistic experiments. 


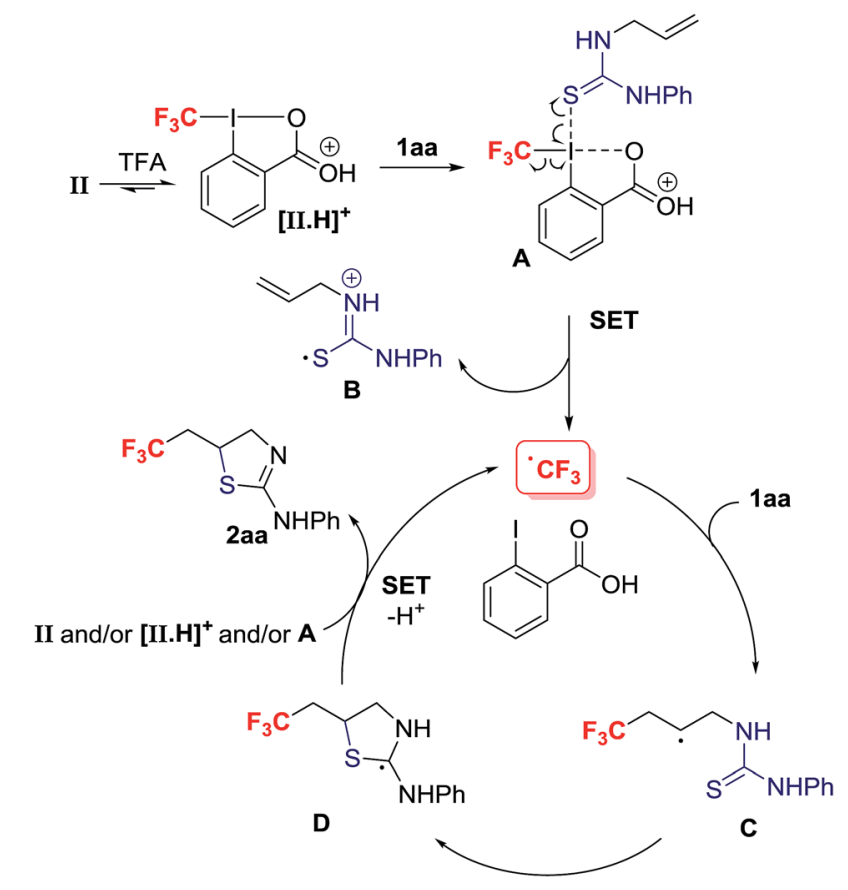

Scheme 4 Proposed mechanism.

and amide 8 (eqn (3)). We found that $\mathbf{6}$ and $\mathbf{8}$ did not react under the standard reaction conditions. Notably, the cyclized products 7 and 9 were isolated in $13 \%$ and $22 \%$ yield respectively, when the trifluoromethylation was performed in the presence of 1 equiv. of DPTU. In a similar vein, 1-allyl-3-phenylurea 10 did not react under the standard reaction conditions, but was consumed in the presence of DPTU with evidence that $\mathrm{CF}_{3}$ radical addition to the alkene took place, but cyclization to $\mathbf{1 1}$ did not occur (eqn (4))..$^{15}$ The thiourea therefore acts as an activator leading to $\mathrm{CF}_{3} \cdot$ formation, and subsequent addition of this radical on the $\mathrm{C}=\mathrm{C} \pi$ bond. The contrasting reactivity of thiourea and urea is consistent with their oxidation potentials $\left(+1.19 \mathrm{~V} v s\right.$. SCE in $\mathrm{CH}_{3} \mathrm{CN}$ for thiourea 1aa and $+1.56 \mathrm{~V} v s$. SCE in $\mathrm{CH}_{3} \mathrm{CN}$ for urea 10); similar values were found for cyclic voltammetry measurements performed in $\mathrm{CH}_{3} \mathrm{CN}$ in the presence of TFA..$^{15}$ Moreover, thioureas are superior to ureas for their ability to react with radical acceptor, an additional factor that accounts for the observed difference of reactivity. We considered next thioamides and thiols as alternative S-sources. Under our standard reaction conditions, the thioamide $\mathbf{1 2}$ failed to provide the product of thiotrifluoromethylation, but led instead to the corresponding amide 13 (eqn (5)). ${ }^{\mathbf{1 5}, 21}$ Pent-4ene-1-thiol 14 underwent intramolecular thiol-ene ring closure and side reactions other than $\mathrm{S}-\mathrm{CF}_{3}$ bond formation or oxidative S-S dimerization (eqn (6)). ${ }^{15,22}$ The thiourea is therefore unique to enable orchestrated alkene trifluoromethylation followed by $S$-cyclization.

Mechanistically, we discarded the possibility of $S$-cyclization prior to trifluoromethylation because this sequence would convert alkenes such as 1na into a thiazoline via 5-exo-trig cyclization, and the thiazine anti-2na is the only product observed in the crude reaction mixture (eqn (2)). ${ }^{23}$ We propose that activation of the Togni reagent II with TFA affords the highly electrophilic iodine(III) species [II.H] that can associate with 1aa via iodine-sulphur coordination leading to A. Coordination of thiourea to the highly electrophilic I(III) in [II.H $]^{+}$is unprecedented, but S-I(III) coordination has been evoked in the $\mathrm{S}_{-} \mathrm{CF}_{3}$ bond formation for thiols reacting with the Togni reagent. ${ }^{24}$ Homolytic dissociation releases $\mathbf{B}$, iodobenzoic acid and the electrophilic radical $\mathrm{CF}_{3}{ }^{\circ}$, which is suited to add regioselectively to the alkene substrate 1aa. The alternative dissociative electron transfer pathway towards $\mathrm{CF}_{3}$ radical formation is also plausible. The resultant carbon radical $\mathbf{C}$ undergoes ring closure with $\mathrm{C}-\mathrm{S}$ bond formation to provide adduct $\mathbf{D}$, which should be easier to oxidize than $\mathbf{C}$; SET to the Togni reagent II, [II.H $]^{+}$and/or $\mathbf{A}$ affords after proton transfer 2aa, and $\mathrm{CF}_{3} \cdot$ that starts a new reaction cycle. ${ }^{25}$ For radicals arising from $\mathrm{CF}_{3} \cdot$ addition to aryl-substituted alkenes, oxidation prior to $S$-cyclization is viable (Scheme 4 ).

\section{Conclusions}

In summary, we developed the first trifluoromethylation followed by $S$-cyclization across $\mathrm{C}=\mathrm{C} \pi$ bonds using thiourea as the S-source. The substrate itself, through its thiourea functionality, acts as an initiator, thereby avoiding metal species or light/photoredox catalysts to induce facile formation of the $\mathrm{CF}_{3}$ radical that adds to the alkene. Thiourea can react with $\mathrm{C}$ centered radical, so a range of alkenes including unactivated systems underwent facile thio-trifluoromethylation. This reaction is an attractive method for medicinal and other applications, because of its broad substrate scope, anti-selectivity and operational simplicity. The discovery that $N, N$-diphenylthiourea is an effective additive to induce the trifluoromethylationcyclization of ureas and benzamides opens the possibility to investigate the value of this category of activators for the development of novel metal-free trifluoromethylation across double bonds.

\section{Acknowledgements}

The authors thank Eli Lilly (P. R.), the Royal Thai Government and SCI (T. K.), and the EU (FP7-PEOPLE-2012-ITN-RADIOMI316882 to L. P.) for generous funding. V. G. thanks the Royal Society for a Wolfson Research Merit Award, and Prof. S. Zard (Ecole Polytechnique, France) and Prof. J. Burton (University of Oxford, UK) for very helpful discussions.

\section{Notes and references}

1 S. Purser, P. R. Moore, S. Swallow and V. Gouverneur, Chem. Soc. Rev., 2008, 37, 320.

2 For a recent review, see: E. Merino and C. Nevado, Chem. Soc. Rev., 2014, 43, 6598. For metal-catalysed and photochemical trifluoromethylation across alkenes, see: (a) A. T. Parsons and S. L. Buchwald, Angew. Chem., Int. Ed., 2011, 50, 9120; Angew. Chem., 2011, 123, 9286; (b) J. Xu, Y. Fu, Y. D. Luo, Y. Jiang, B. Xiao, Z. Liu, T. Gong and L. Liu, J. Am. Chem. Soc., 2011, 133, 15300; (c) X. Wang, Y. Ye, S. Zhang, J. Feng, 
Y. Xu, Y. Zhang and J. Wang, J. Am. Chem. Soc., 2011, 133, 16410; (d) R. Shimizu, H. Egami, Y. Hamashima and M. Sodeoka, Angew. Chem., Int. Ed., 2012, 51, 4577; Angew. Chem., 2012, 124, 4655; (e) S. Mizuta, O. Galicia-López, K. M. Engle, S. Verhoog, K. Wheelhouse, G. Rassias and V. Gouverneur, Chem.-Eur. J., 2012, 18, 8583; (f) P. G. Janson, I. Ghoneim, N. O. Iichenko and K. J. Szabó, Org. Lett., 2012, 14, 2882; $(g)$ Y. Yasu, T. Koike and M. Akita, Angew. Chem., Int. Ed., 2012, 51, 9567; Angew. Chem., 2012, 124, 9705; (h) R. Zhu and S. L. Buchwald, J. Am. Chem. Soc., 2012, 134, 12462; (i) R. Zhu and S. L. Buckwald, Angew. Chem., Int. Ed., 2013, 52, 12655; Angew. Chem., 2013, 125, 12887; (j) C. Feng and T.-P. Loh, Chem. Sci., 2012, 3, 3458; (k) X. Wu, L. Chu and F. Qing, Angew. Chem., Int. Ed., 2013, 52, 2198; Angew. Chem., 2013, 125, 2254; (l) H. Egami, S. Kawamura, A. Miyazaki and M. Sodeoka, Angew. Chem., Int. Ed., 2013, 52, 7841; Angew. Chem., 2013, 125, 7995; (m) C. Feng and T.-P. Loh, Angew. Chem., Int. Ed., 2013, 52, 12414; Angew. Chem., 2013, 125, 12640; (n) N. O. Ilchenko, P. G. Janson and K. J. Szabó, Chem. Commun., 2013, 49, 6614; (o) S. Mizuta, S. Verhoog, K. M. Engle, T. Khotavivattana, M. O'Duill, K. Wheeelhouse, G. Rassias, M. Médebielle and V. Gouverneur, J. Am. Chem. Soc., 2013, 135, 2505; ( $p)$ X. Wu, L. Chu and F.-L. Qing, Angew. Chem., Int. Ed., 2013, 52, 2198; Angew. Chem., 2013, 125, 2254. For metal-free trifluoromethylation across alkenes, see: $(q)$ Y. Li and A. Studer, Angew. Chem., Int. Ed., 2012, 51, 8221; Angew. Chem., 2012, 124, 8345; (r) B. Zhang, C. Muck-Lichtenfeld, C. G. Daniliuc and A. Studer, Angew. Chem., Int. Ed., 2013, 52, 10792; Angew. Chem., 2013, 125, 10992; (s) D. J. Wilger, N. J. Gesmundo and D. A. Nicewicz, Chem. Sci., 2013, 4, 3160; $(t)$ W. Kong, M. Casimiro, N. Fuentes, E. Merino and C. Nevado, Angew. Chem., Int. Ed., 2013, 52, 13086; Angew. Chem., 2013, 125, 13324; (u) H. Egami, Y. Usui, S. Kawamura, S. Nagashima and M. Sodeoka, Chem.-Asian J., 2015, 10, 2190; (v) N.-Y. Yang, Z.-L. Li, L. Ye, B. Tan and X.-Y. Liu, Chem. Commun., 2016, 52, 9052.

3 X.-H. Xu, K. Matsuzaki and N. Shibata, Chem. Rev., 2015, 115, 731.

4 T. Billard, R. Roques and B. R. Langlois, Tetrahedron Lett., 2000, 41, 3069. For a trifluoromethylchlorosulfonylation, see: D. B. Bagal, G. Kachkovskyi, M. Knorn, T. Rawner, B. N. Bhanage and O. Reiser, Angew. Chem., Int. Ed., 2015, 54, 6999; Angew. Chem., 2015, 127, 7105.

5 F. Bertrand, V. Pevere, B. Quiclet-Sire and S. Zard, Org. Lett., 2001, 3, 1069.

6 For a review, see: M. Feng, B. Tang, S. H. Tang and X. Jiang, Curr. Top. Med. Chem., 2016, 16, 1200.

7 Z. Liang, F. Wang, P. Cheng and G. Liu, Org. Lett., 2015, 17, 2438.

8 (a) M. Asif, Journal of Pharmaceutical and Applied Chemistry, 2015, 1, 49; (b) G. Makhaeva, N. Boltneva,
S. V. Lushchekina, O. G. Serebryakova, T. S. Stupina, A. A. Terentiev, I. V. Serkov, A. N. Proshin, O. G. Bachurin and R. J. Richardson, Bioorg. Med. Chem., 2016, 24, 1050.

9 (a) A. K. Ghosh and H. L. Osswald, Chem. Soc. Rev., 2014, 43, 6765; (b) R. Vassar, Alzheimer's Res. Ther., 2014, 6, 89; (c) L. L. Winneroski, M. A. Schiffler, J. A. Erickson, P. C. May, S. A. Monk, D. E. Timm, J. E. Audia, J. P. Beck, L. N. Boggs, A. R. Borders, R. D. Boyer, R. A. Brier, K. J. Hudziak, V. J. Klimkowski, G. P. Losada, B. M. Mathes, S. L. Stout, B. M. Watson and D. J. Mergott, Bioorg. Med. Chem., 2015, 23, 3260.

10 The ionization potential of urea and thiourea is $10.27 \mathrm{eV}$ and $8.5 \mathrm{eV}$ respectively. M. Baldwin, A. Kirkien-Konasiewicz, A. G. Loudon, A. Maccoll and D. Smith, Chem. Commun., 1966, 574.

11 (a) M. Wasil, B. Halliwell, M. Grootveld, C. P. Moorhouse, D. C. Hutchison and H. Baum, Biochem. J., 1987, 243, 867; (b) M. Whiteman and B. Halliwell, Free Radical Biol. Med., 1997, 22, 1309; (c) M. C. Araujo, L. M. Antunes and C. S. Takahashi, Teratog., Carcinog. Mutagen., 2001, 21, 175.

12 J. Charpentier, N. Früh and A. Togni, Chem. Rev., 2015, 115, 650.

13 P. Eisenberger, S. Gishig and A. Togni, Chem.-Eur. J., 2006, 12, 2579.

14 (a) T. Umemoto and S. Ishihara, Tetrahedron Lett., 1990, 31, 3579; (b) T. Umemoto and S. Ishihara, J. Am. Chem. Soc., 1993, 115, 2156; (c) T. Umemoto, Chem. Rev., 1996, 96, 1757. 15 For details, see the ESI. $\dagger$

16 (a) R. Koller, Q. Huchet, P. Battaglia, J. M. Welch and A. Togni, Chem. Commun., 2009, 5993; (b) J. N. Brantley, A. V. Samant and F. D. Toste, ACS Cent. Sci., 2016, 2, 341.

17 N. Noto, K. Miyazawa, T. Koike and M. Akita, Org. Lett., 2015, 17, 3710 .

18 S. V. Blokhina, T. V. Volkova, M. V. Ol'khovich, A. V. Sharapova, A. N. Proshin, S. O. Bachurin and G. L. Perlovich, Eur. J. Med. Chem., 2014, 77, 8.

19 A. E. Minatti, J. D. Low, J. R. Allen, J. Chen, Y. Cheng, T. Judd, Q. Liu, P. Lopez, W. Quia, R. Rumfelt, N. Rzasa, Q. X. Tamayo, B. Yang and W. Zhong, WO2013142613A1, 2014.

20 A. Studer, Angew. Chem., Int. Ed., 2012, 51, 8950; Angew. Chem., 2012, 124, 9082.

21 In the absence of TFA, thioamide 10 undergoes oxidative dimerization. I(III)-Mediated conversion of thioamide into amide is known N. K. Downer-Riley and Y. A. Jackson, Tetrahedron, 2008, 64, 7741.

22 C. E. Hoyle and C. N. Bowman, Angew. Chem., Int. Ed., 2010, 49, 1540; Angew. Chem., 2010, 122, 1584.

23 P. D. Morse and D. A. Nicewicz, Chem. Sci., 2015, 6, 270.

24 O. Sala, N. Santschi, S. Jungen, H. P. Lüthi, M. Iannuzzi, N. Hauser and A. Togni, Chem.-Eur. J., 2016, 22, 1704.

25 The oxidation of $\mathbf{D}$ with $\mathbf{B}$ regenerates $\mathbf{1 a a}$. 